\title{
Short term reduction of left ventricular mass in primary hypertrophic cardiomyopathy by octreotide injections
}

A thsan Günal, Ahmet Işık, Hüseyin Çeliker, Orhan Eren, Harika Çelebi, Servin Y Günal, Cemal Lüleci

\begin{abstract}
Growth factors have been shown to be associated with primary hypertrophic cardiomyopathy. Octreotide, a long acting somatostatin analogue, can prevent the stimulating effect of growth factors and decrease the left ventricular mass in patients with acromegaly. In the light of these results, three patients with primary hypertrophic cardiomyopathy were treated with subcutaneous octreotide (50 $\mu \mathrm{g}$ three times a day during the first week and $100 \mu \mathrm{g}$ twice a day for the following three weeks). Initially, two patients were in New York Heart Association class II in and one was in class III. At the end of a four week treatment session all were in class I. There were significant decreases in left ventricular posterior wall thickness, interventricular septum thickness, and left ventricular mass in all three patients. Both left ventricular end diastolic and end systolic diameters had increased in all of the patients at the end of the fourth week. Two of three patients showed improved diastolic filling: their hyperdynamic systolic performance returned to normal. No side effects were observed during octreotide treatment.

The considerable improvement obtained with the short term octreotide treatment in patients with primary hypertrophic cardiomyopathy seems promising.
\end{abstract}

(Heart 1996;76:418-421)

Keywords: hypertrophic cardiomyopathy; octreotide

Hypertrophic cardiomyopathy has characteristic morphological features such as a hypertrophied and non-dilated left ventricle. ${ }^{1}$ The myocardium typically shows disorganised cellular architecture, abnormally small intramural coronary arteries, and increased amounts of matrix or replacement fibrosis. ${ }^{2}$ Several mechanisms may contribute to the development of ventricular hypertrophy in hypertrophic cardiomyopathy. In earlier studies in patients with hypertrophic cardiomyopathy the response of the cardiovascular system to noradrenaline was increased, the sensitivity of the $\beta$ adrenergic receptor was enhanced, and cardiac neuronal noradrenaline uptake was impaired. ${ }^{34}$ An increase in calcium uptake and the calcium content of myocardium has also been reported. ${ }^{5}$ The administration of nerve growth factor has been reported to increase catecholamine concentrations and cause hypertrophy and disarray in the myocardial fibres of dogs. ${ }^{6}$ Toyozaki et al reported that insulin-like growth factor-I specific receptors are present in adult human cardiac myocytes. ${ }^{7}$ Their data suggest that insulin-like growth factor-I receptors are related to the development of myocyte hypertrophy in hypertrophic cardiomyopathy. Sakata showed that the activities of transforming growth factor-I and angiotensin converting enzyme were increased in cardiomyopathic hamsters. ${ }^{8}$

Octreotide, a long acting somatostatin analogue, was shown to prevent the stimulating effect of growth factors ${ }^{9}$ and inhibit noradrenaline-induced intracellular calcium uptake. ${ }^{10}$ In addition, octreotide reduced left ventricular hypertrophy in patients with acromegaly. ${ }^{11-13}$

In this study, three patients with primary hypertrophic cardiomyopathy were treated with octreotide. The plasma growth hormone concentrations were measured by radioimmunoassay (Orion Diagnostica, Espoo, Finland). The fasting baseline growth hormone concentrations of all cases were in the normal range $(8.4 \mathrm{mIU} / \mathrm{ml}(3.0 \mu \mathrm{g} / \mathrm{l})$ in case 1 , $7.9 \mathrm{mIU} / \mathrm{ml}(2.82 \mu \mathrm{g} / \mathrm{l})$ in case $2,5.1 \mathrm{mIU} / \mathrm{ml}$ $(1.8 \mu \mathrm{g} / \mathrm{l}$ ) in case 3 (normal range $0-14$ $\mathrm{mIU} / \mathrm{ml}(0-5 \mu \mathrm{g} / \mathrm{l})$ in adults)). After systemic hypertension, valvar aortic stenosis, aortic coarctation, pheochromocytoma, amyloidosis, acromegaly, hyperparathyroidism, neurofibromatosis, and generalised lipodystrophy had been excluded the diagnosis of primary hypertrophic cardiomyopathy was made by echocardiography. Informed consent was obtained from each patient. The Ethics Committee of The Firat University Hospital approved the study design.

Octreotide was given subcutanously three times $(50 \mu \mathrm{g})$ a day during the first week and twice $(100 \mu \mathrm{g})$ a day for the following three weeks. Maintenance therapy with an angiotensin converting enzyme inhibitor, perindopril ( $2 \mathrm{mg}$ daily), was also given because the cardiovascular system of patients with primary hypertrophic cardiomyopathy showed an increased response to adrenaline ${ }^{34}$ and increased activity of angiotensin converting enzyme was seen in cardiomyopathic hamsters. ${ }^{8}$ Moreover, angiotensin converting enzyme inhibitors have been shown to decrease left ventricular mass in patients with essential hypertension. ${ }^{14} 15$

During the treatment period, clinical findings, biochemical tests, and electrocardiographic and echocardiographic results were
Correspondence to: Tuliker, Firat Universitesi, Anabilim Dalı 23119 Elaziğ, Turkey.

Accepted for publication 20 June 1996 
Table $1 M$ mode variables in patients before treatment and during the first, second, third and fourth weeks of octreotide treatment

\begin{tabular}{|c|c|c|c|c|c|c|c|c|c|c|c|c|c|c|}
\hline \multirow[b]{2}{*}{ Variable } & \multicolumn{5}{|l|}{ Case 1} & \multicolumn{4}{|l|}{ Case 2} & \multicolumn{5}{|l|}{ Case 3} \\
\hline & $B$ & 1 & 2 & 3 & 4 & $B$ & 1 & 2 & 4 & $B$ & 1 & 2 & 3 & 4 \\
\hline $\begin{array}{l}\text { LVPW } \\
\text { IVS } \\
\text { EDD } \\
\text { ESD } \\
\text { LVM }\end{array}$ & $\begin{array}{r}22 \cdot 3 \\
23 \cdot 5 \\
36 \cdot 5 \\
20 \cdot 2 \\
516 \cdot 2\end{array}$ & $\begin{array}{r}19.8 \\
19.3 \\
38.3 \\
23.7 \\
411.0\end{array}$ & $\begin{array}{r}17 \cdot 6 \\
18 \cdot 3 \\
41 \cdot 0 \\
24 \cdot 2 \\
386 \cdot 7\end{array}$ & $\begin{array}{r}16.7 \\
17 \cdot 7 \\
41.7 \\
24.5 \\
377 \cdot 2\end{array}$ & $\begin{array}{r}16.0 \\
16.3 \\
41.8 \\
24.8 \\
334.4\end{array}$ & $\begin{array}{r}13 \cdot 2 \\
18.8 \\
41.0 \\
24 \cdot 0 \\
319 \cdot 1\end{array}$ & $\begin{array}{r}12 \cdot 0 \\
16 \cdot 8 \\
43 \cdot 0 \\
23 \cdot 7 \\
288 \cdot 6\end{array}$ & $\begin{array}{r}12 \cdot 0 \\
15 \cdot 5 \\
43 \cdot 2 \\
23 \cdot 5 \\
277 \cdot 0\end{array}$ & $\begin{array}{r}11.2 \\
15.0 \\
44.2 \\
25.3 \\
285.5\end{array}$ & $\begin{array}{r}17 \cdot 2 \\
24 \cdot 3 \\
30 \cdot 3 \\
15 \cdot 8 \\
342 \cdot 4\end{array}$ & $\begin{array}{r}16 \cdot 8 \\
17 \cdot 7 \\
34 \cdot 0 \\
20 \cdot 2 \\
279 \cdot 7\end{array}$ & $\begin{array}{r}14 \cdot 7 \\
16 \cdot 8 \\
35 \cdot 2 \\
22 \cdot 5 \\
249 \cdot 6\end{array}$ & $\begin{array}{r}14.4 \\
16.0 \\
35.5 \\
20 \cdot 6 \\
247.2\end{array}$ & $\begin{array}{r}14 \cdot 2 \\
16 \cdot 0 \\
36 \cdot 3 \\
22 \cdot 0 \\
242 \cdot 5\end{array}$ \\
\hline
\end{tabular}

LVPW, left ventricular posterior wall thickness (mm); IVS, interventricular septum thickness (mm); EDD, end diastolic diameter $(\mathrm{mm})$; ESD, end systolic diameter $(\mathrm{mm})$; LVM, left ventricular mass $(\mathrm{g})$; B, before treatment.

strictly monitored. Echocardiograms were obtained with a $2.5 \mathrm{MHz}$ transducer from the left parasternal window. Cross sectionally guided $M$ mode tracings were obtained in the parasternal long-axis view from the mitral valve leaflets. The transducer position was adjusted to ensure that the $M$ mode cursor made a perpendicular cut through the left ventricle. Left ventricular cavity, septal, and posterior wall dimensions were measured at end diastole and end systole, as defined by an electrocardiographic tracing. All dimensional measurements were made using a leading edge-to-edge convention by an experienced echocardiographer who was blinded to the design of the study. ${ }^{16}$ The mean values for each patient were obtained after six measurements. The left ventricular mass was calculated according to the Penn formula. ${ }^{17}$

Fractional shortening, mean velocity of circumferential fiber shortening, and ejection fraction were used in the assessment of left ventricular systolic performance. Peak flow velocities of the early and late diastolic fillings and their ratio were used in association with the transmitral flow sample to assess left ventricular diastolic performance.

\section{Case 1}

A 33 year old man had been diagnosed as having primary hypertrophic cardiomyopathy nine years before. He had been treated intermittently with propranolol or verapamil before octreotide was tried. His functional capacity was class II (New York Heart Association criteria (NYHA)). At physical examination, his blood pressure was $115 / 75 \mathrm{~mm} \mathrm{Hg}$. His heart rate was regular ( 72 beats $/ \mathrm{min}$ ). There was slight apical deviation to left lateral side and a double impulse at the apex. Left ventricular activity was $2(+)$ and the fourth heart sound was heard. On the chest $x$ ray the contour of the left ventricle was prominently curved. The

Table 2 Systolic and diastolic performance indices of patients before treatment and during the fourth week of octreotide treatment

\begin{tabular}{|c|c|c|c|c|c|c|}
\hline \multirow[b]{2}{*}{ Index } & \multicolumn{2}{|l|}{ Case 1} & \multicolumn{2}{|l|}{ Case 2} & \multicolumn{2}{|l|}{ Case 3} \\
\hline & Baseline & $4 w$ & Baseline & $4 w$ & Baseline & $4 w$ \\
\hline $\begin{array}{l}\text { FS } \\
\text { VHF } \\
\text { EF } \\
\text { E } \\
\text { A } \\
\text { E/A }\end{array}$ & $\begin{array}{l}44 \\
2 \cdot 12 \\
83 \\
51 \\
50 \\
1 \cdot 02\end{array}$ & $\begin{array}{l}40 \\
1 \cdot 89 \\
73 \\
52 \\
42 \\
1 \cdot 23\end{array}$ & $\begin{array}{l}40 \\
1 \cdot 80 \\
80 \\
87 \\
50 \\
1 \cdot 70\end{array}$ & $\begin{array}{l}43 \\
1 \cdot 28 \\
81 \\
84 \\
54 \\
1 \cdot 60\end{array}$ & $\begin{array}{l}47 \\
2 \cdot 26 \\
85 \\
54 \\
61 \\
0 \cdot 88\end{array}$ & $\begin{array}{c}39 \\
1.65 \\
77 \\
45 \cdot 5 \\
33.5 \\
1 \cdot 36\end{array}$ \\
\hline
\end{tabular}

FS, fractional shortening (\%); VCF, frequency normalised mean velocity of circumferential fibre shortening (circ/s); EF, ejection fraction (\%); E, peak early diastolic mitral velocity $(\mathrm{cm} / \mathrm{s})$ $\mathrm{A}$, peak late diastolic mitral velocity $(\mathrm{cm} / \mathrm{s}) ; \mathrm{E} / \mathrm{A}$, peak early/late diastolic mitral velocity. electrocardiogram showed sinus rhythm, $\mathrm{P}$ pulmonale ( $P$ wave $0.6 \mathrm{mV}$ in lead II), left ventricular hypertrophy $(\mathrm{V} 1 \mathrm{~S}+\mathrm{V} 5 \mathrm{R}=10 \cdot 2$ $\mathrm{mV})$, inverted $\mathrm{T}$ waves $(0.3 \mathrm{mV}$ in I and aVL; $0.7 \mathrm{mV}$ in V5; $0.4 \mathrm{mV}$ in V6), and ST segment elevation $(0.3 \mathrm{mV}$ in $\mathrm{V} 2$ and $\mathrm{V} 3)$. $\mathrm{M}$ mode variables at the baseline and during the first, second, third, and fourth weeks are shown in table 1. Systolic and diastolic variables at baseline and during the fourth week are shown in table 2 .

At the end of the first week, blood pressure was $120 / 70 \mathrm{~mm} \mathrm{Hg}$ and heart rate was 64 beats/min. $P$ wave was $0.4 \mathrm{mV}$ and $\mathrm{T}$ waves in leads V5 and V6 were diphasic.

At the end of four weeks treatment, the functional capacity was class I. The heart rate and systolic blood pressure were stable between 70 and 74 beats/min and 115 and $130 \mathrm{~mm} \mathrm{Hg}$ respectively. The $P$ wave was $0.3 \mathrm{mV}$. $T$ waves were still inverted but not to the same extent as they were initially. The left ventricular mass was $35 \%$ smaller.

\section{Case 2}

Primary hypertrophic cardiomyopathy had been diagnosed in this 25 year old man six months before. He had been treated with mexiletine or amiodarone for his arrhythmias before octreotide was given. His functional capacity was class II. Blood pressure was $140 / 70 \mathrm{~mm} \mathrm{Hg}$ and heart rate was 79 beats/min. There was double impulse at the apex. Left ventricular activity was $1(+)$. The fourth heart sound was heard. Electrocardiography showed sinus rhythm, left anterior hemiblock, ventricular hypertrophy (V1S+V5R $=4.6 \mathrm{mV}$ ), inverted $\mathrm{T}$ waves (in lead I, aVL), ST segment elevation (in lead V1-4), and giant $T$ waves (in leads V1-4). This patient did not attend the follow up examination at three weeks. $M$ mode variables before the treatment and during the first, the second, and the fourth weeks are shown in table 1. Table 2 shows systolic and diastolic performance indices before the treatment and during the fourth week.

Nodal premature systoles with a rate of 7-8 beats/minute that had been observed on the previous electrocardiograms reappeared on the second treatment day. The inverted $T$ waves became positive in lead I and diphasic in lead $\mathrm{aVL}$ on the second treatment day. At the end of the first week, there was no change in blood pressure and heart rate. $T$ waves in lead aVL were inverted again. Amiodarone was added to the treatment on the tenth day. 
At the end of the four weeks of treatment, his functional capacity improved from class II to class I. T waves became diphasic in lead I and inverted in lead aVL on electrocardiography. The left ventricular mass decreased by $19 \%$.

\section{Case 3}

This 34 year old man had had primary hypertrophic cardiomyopathy for eight years and had been regularly treated with propranolol or verapamil before octreotide treatment. He was the brother of case one. Diazepam had been recently added to his treatment. His functional capacity was assessed as class III. Blood pressure was $80 / 40 \mathrm{~mm} \mathrm{Hg}$ and heart rate 84 beats/min; the apex was slightly deviated to the left lateral side. There was double impulse at the apex and left ventricular activity was $2(+)$. The fourth heart sound was also heard. On the chest $x$ ray the contour of the left ventricle was prominently curved. Electrocardiography showed sinus rhythm, $P$ pulmonale $(0.6 \mathrm{mV}$ in lead II), left ventricular hypertrophy $(\mathrm{V} 1 \mathrm{~S}+\mathrm{V} 5 \mathrm{R}=6.4 \mathrm{mV})$, and inverted $\mathrm{T}$ waves (in leads $\mathrm{I}$, aVL, V5, and V6). His $\mathrm{M}$ mode variables before treatment and during first, second, third, and fourth weeks are shown in table 1. Table 2 shows his systolic and diastolic performance indices before the treatment and during the fourth week.

At the end of the first week's treatment, blood pressure was $100 / 70 \mathrm{~mm} \mathrm{Hg}$ and heart rate was 65 beats $/ \mathrm{min}$. The $P$ wave was 0.4 $\mathrm{mV}$ and $\mathrm{T}$ waves in lead $\mathrm{I}, \mathrm{aVL}, \mathrm{V} 5$, and V6 were diphasic.

At the end of the four weeks' treatment, his functional capacity had improved from class III to class I. The heart rate and systolic blood pressure were stable between 70 and 75 beats/min and 100 and $110 \mathrm{~mm} \mathrm{Hg}$ respectively. The $P$ wave was $0.4 \mathrm{mV}$ and $T$ waves in lead I and V5 and V6 became positive. The left ventricular mass had decreased by $29 \%$.

No side effects were seen in any of the three patients during octreotide treatment.

\section{Discussion}

Treatment of patients with primary hypertrophic cardiomyopathy is directed to relieve the symptoms, to prevent the complications, and to reduce the risk of death. ${ }^{18}$ Propranolol and calcium-entry-blocking agents are the mainstay of medical treatment in symptomatic hypertrophic cardiomyopathy. ${ }^{19}$ Various surgical procedures aimed at reducing the outflow gradient are commonly used in markedly symptomatic patients who have not responded well to medical management. ${ }^{20}$

Octreotide has been used to inhibit the release of growth hormone for more than 10 years. ${ }^{21}$ Somatostatin analogues, such as octreotide and angiopeptin, have been shown to have direct antiproliferative effects in a wide range of cell types in vitro and in vivo. ${ }^{22}$ Coupling of growth factor and receptor has several consequences. ${ }^{23}$ Binding of growth factor induces autophosphorylation of the $\beta$ sub- unit of the receptor and activates a tyrosine kinase. Inactivation of receptors for these growth factors involves specific protein tyrosine phosphatases. $^{24}$ Somatostatin activates specific protein tyrosine phosphatases and can inhibit the stimulating effect of growth factors. ${ }^{9}$ Moreover, octreotide has an antiproliferative effect by increasing the synthesis of insulin-like growth factor-I binding protein independently of growth hormone. ${ }^{25}$

To our knowledge no data about octreotide therapy in patients with primary hypertrophic cardiomyopathy have been reported. Octreotide reduced left ventricular hypertrophy in patients with acromegaly. ${ }^{11-13}$ Decreased interstitial oedema or myocyte regression were proposed as the mechanisms of regression. ${ }^{11}$ Primary hypertrophic cardiomyopathy and cardiac hypertrophy in acromegalic patients are different entities. However, it is possible that post-receptor events may be the common pathway in two diseases. After a six months octreotide treatment, Tokgözoglu et al found that left ventricular mass decreased from 304 to $175 \mathrm{~g}$ in six patients with acromegaly. ${ }^{11}$ Similarly, Merola et al showed that left ventricular mass decreased by $18 \%$ in 11 patients with acromegaly..$^{12}$ In our study, after one month of octreotide treatment left ventricular mass decreased by $35 \%, 19 \%$, and $29 \%$ in cases 1,2 , and 3 respectively (mean $24 \%$ ). The differences between regression of left ventricular hypertrophy in patients with acromegaly and our patients may be attributed to the differences in sample numbers, doses of drug, and the duration of treatments. Moreover, these are two different diseases. We think that patients with primary hypertrophic cardiomyopathy are more sensitive to octreotide than acromegalic patients: there was a reduction of $24 \%$ in left ventricular mass within four weeks with a lower dose of octreotide in patients with primary hypertrophic cardiomyopathy compared with the reduction of $18 \%$ within six months with a higher dose of octreotide in patients with acromegaly. ${ }^{12} \mathrm{Lim}$ et al suggested that left ventricular hypertrophy in acromegaly was caused by chronic growth hormone hypersecretion from a pituitary tumour and that the reduction of myocardial mass during octreotide therapy was related to the suppression of growth hormone hypersecretion. ${ }^{13}$ Therefore a higher dose of octerotide and long term treatment may be needed in acromegaly because it may be difficult to suppress a tumour.

In our patients, the accelerated regression of left ventricular hypertrophy observed in the first week, which gradually became slower in the following weeks, may be due to low drug dose or fibrosis, which can not regress. Regression of left ventricular hypertrophy observed in the first week may be attributed to the antioedema effect of octreotide, but the long term regression may be related to myocyte regression, which might be caused by inhibition of growth factors by octreotide in our patients as it is in acromegaly. ${ }^{11}$

Functionally, the left ventricle is hyperdy- 
namic in systole and displays delayed relaxation and decreased compliance in diastole. It has been shown that octreotide treatment can reduce left ventricular mass without having an adverse effect on the left ventricular contractile state ${ }^{1112}$ and that it improves ventricular diastolic filling ${ }^{12}$ in acromegalic patients. In two of our three patients, diastolic filling improved while the hyperdynamic systolic performance returned to normal values.

Merola et al reported that there was no significant change in left ventricular chamber dimensions at six months. ${ }^{12}$ Tokgözoḡlu et al found that left ventricular end diastolic diameter was increased and end systolic diameter was decreased slightly at six months. ${ }^{11} \mathrm{Lim}$ et al observed that patients with left ventricular hypertrophy had a small increase in left ventricular end systolic diameter at two months. ${ }^{13}$ The pathogenesis of these changes in left ventricular chamber dimensions has not been explained. Cardiac enlargement in our cases may be due to reduced wall thickness and improved compliance. Six months later, wall thickness and left ventricular end diastolic and end systolic diameters of all patients were at the baseline values without progressive ventricular dilatation.

Patients with hypertrophic cardiomyopathy may have angina and electrocardiographic abnormalities consistent with ischaemia and infarction. There are several potential mechanisms responsible for myocardial ischaemia in hypertrophic cardiomyopathy: (a) excessive myocardial oxygen demand that exceeds the capacity of the coronary system to deliver oxygen, (b) compromised coronary blood flow to the myocardium due to narrowed intramural coronary arteries, $(c)$ prolonged diastolic relaxation resulting in increased myocardial wall tension. ${ }^{226}$ The amelioration of electrocardiographic abnormalities in our patients may be related to increased coronary flow which might have been caused by the inhibition of the smooth muscle cells of the intramural coronary arteries by octreotide. ${ }^{22}$ In addition, reduced- left ventricular mass and both a decrease in systolic function and an improvement in diastolic relaxation and filling may improve electrocardiographic abnormalities.

However, left ventricular mass returned to the baseline value in all patients in six months despite the maintenance therapy with perindopril. We believe that until the prescription of depot forms of octreotide becomes possible, intermittent treatment will be needed in primary hypertrophic cardiomyopathy.

Our study had several limitations. The functional capacity could not be assessed by an exercise tolerance test. NYHA classification might not reflect actual functional capacity in hypertrophic cardiomypathy. In addition, endomyocardial biopsies could not be performed and myocardial concentrations of insulin-like growth factor I were not determined.

This study has been presented as a preliminary report. We believe that further larger studies are needed to asses the effi- cacy of octreoctide treatment in primary hypertrophic cardiomyopathy. In conclusion, the dramatic improvement seen after short term octreotide treatment in patients with primary hypertrophic cardiomyopathy seems promising.

1 Maron BJ, Epstein SE. Hypertrophic cardiomyopathy: a discussion of nomenclature. Am 7 Cardiol 1979;43. discussion

2 Maron BJ, Wolfson JK, Epstein SE, Roberts WC. Intramural coronary artery disease in hypertrophic cardiomyopathy. $\mathcal{F} \mathrm{Am}$ Coll Cardiol 1986;8:545-57.

3 Yoshinori K, Morio I, Hironori T. Increased cardiovascular response to epinephrine in hypertrophic cardiomyopathy. fpn Heart f 1985;26:727-40.

4 Brush JE, Eisenhofer G, Garty M, Stull R, Maron BJ, Canon $\mathrm{RO}$, et al. Cardiac norepinephrine kinetics in hypertrophic cardiomyopathy. Circulation 1987;79:836-44.

5 Pearce PC, Hawkey C, Symons C, Olsen EGJ. Role of calcium in the induction of cardiac hypertrophy and myofibrillar disarray. Br Heart $\mathcal{F}$ 1985;54:420-7.

6 Witzke AH, Kaye MP. Myocardial ultrastructural changes induces by administration of nerve growth factor. Surg Forum 1976;27:295.

7 Toyozaki T, Hiroe $\dot{M}$, Hasumi $M$, Horie T, Husoda $S$, Tsushima T, et al. Insulin-like growth factor I receptors in human cardiac myocytes and their relation to myocardial hypertrophy. $\mathcal{F p}_{n}$ Circ $\mathcal{F} 1$ 1993;57:1120-7.

8 Sakata $Y$. Tissue factor contributing to cardiac hypertrophy in cardiomyopathic hamsters (BIO 14.6): involvement of transforming growth factor-beta $I$ and tissue reninangiotensin system in the progression of cardiac hypertrophy. Hokkaido Igaku Zasshi 1993;68:18-28.

9 Grant MB, Wargovich TJ, Ellis EA, Caballero BS, Mansour M, Pepine CJ. Localization of insulin-like growth factor I and inhibition of coronary smooth muscle cell growth by somatostatin analogues in human coronary smooth muscle cells. Circulation 1994;89: coronary

10 Zink A, Rause F. Somatostatin inhibits the norepinephrineactivated calcium channels in rMTC 6-23 cells: possible involvement of a pertussis toxin-sensitive G-protein. Acta Endocrinologia 1992;127:378-84.

11 Tokgözoḡlu SL, Erbaş T, Aytemir K, Akalýn S, Kes S, Oram E. Effects of octreotide on left ventricular mass in acromegaly. $A m \mathcal{F}$ Cardiol 1994;74:1072-4.

12 Merola B, Cittadini A, Colao A, et al. Chronic treatment with the somatostatin analog octreotide improves cardiac with the somatostatin analog octreotide improves cardiac 1993;77:790-3.

13 Lim MJ, Barkan AL, Buda AJ. Rapid reduction of left ventricular hypertrophy in acromegaly after suppression of growth hormone hypersecretion. Ann Intern Med 1992; 117:719-26.

14 Opie LH. Angiotensin converting enzyme inhibitors. New York: Authors' Publishing House. 1992;21-153.

15 McAreavey D, Robertson JS. Angiotensin converting enzyme inhibitors and moderate hypertension. Drugs 1990;40:326-45.

16 Sahn DJ, DeMaria A, Kisslo J. Recommendations regarding quantification in $\mathbf{M}$-mode echocardiography: results of a survey of echocardiographic measurements. of a survey of echocartion 1978;58:1072-83.

17 Devereux RB, Alonso DR, Lutas EM, Goltlieb GJ, Campo E, Sachs I, et al. Echocardiographic assessment of left ventricular hypertrophy: Comparison to necropsy findings. Am $\mathcal{F}$ Cardiol 1986;57:450-8.

18 Wynne S, Braunwald E. Hypertrophic cardiomyopathy. In Braunwald E, ed. Heart disease: a textbook of cardiovascular medicine. Philadelphia: WB Saunders, 1992;1412-3.

19 Maron BJ, Bonow CO, Cannon RO, Leon MB, Epstein SE. Hypertrophic cardiomyopathy: interrelation of clinical manifestations, pathysiology and therapy. $N$ Eng f Med 1987;316:780-9; 844-52.

20 McIntosh CL, Moron BJ. Current operative treatment of hypertrophic obstructive cardiomyopathy. Circulation 1988;78:487.

21 Lamberts SW. The role of somatostatin in the regulation of anterior pituitary hormone secretion and the use of its analogs in the treatment of human pituitary tumors. Endocr Rev 1988;9:417-36.

22 Parmar H, Bogden A, Mollard M, de Rouge B, Phillips $\mathrm{RH}$, Lightman SL. Somatostatin and somatostatin analogues in oncology. Cancer Treat Rev 1989;16:95-115.

23 Yarden Y, Ullrich A. Growth factor receptor tyrosine kinases. Annu Rev Biochem 1988;57:443-78.

24 Cool DE, Andreassen PR, Tonks NK, Krebs EG, Fischer $\mathrm{EH}$, Morgolis RL. Cytokinetic failure and asynchronous nuclear division in BHK cells overexpressing a truncated nuclear division in BHK cells overexpressing a truncated protein-tyrosine-ph

25 Ezzat S, Ren SG, Braunstein GD, Melmed S. Octreotide stimulates insulin-like growth factor-binding protein-I: a stimulates insulin-like growth factor-binding protein-I: a
potential pituitary-independent mechanism for drug potential pituitary-independent mechanism for
action. $\mathcal{A}$ Clinical Endocr Metab 1992;75:1459-63.

26 Cannon RO, Rosing DR, Maron BJ, Leon MB, Bonow Cannon RO, Rosing DR, Maron BJ, Leon MB, Bonow
CO, Watson RM. Myocardial ischemia in hypertrophic cardiomyopathy: contribution of inadequate vasodilator reserve and elevated left ventricular filling pressures. Circulation 1985;71:234-43. 